\title{
The Research and Practice in Bilingual Teaching Mode of Automation Major Courses
}

\author{
Chen Zhijun, Li Zheng, Shang Xiaomei, Wang Zhihong \\ School of Electrical Engineering, Hebei University of Science and Technology, Shijiazhuang, \\ 050018, China \\ E-mail: zkong_1@sina.com
}

Keywords: Automation, Major courses, Bilingual teaching

\begin{abstract}
Based on analyzing the problems and basic modes of current bilingual courses teaching, reforms on automation major courses bilingual teaching are necessary and effective. The proper conditions with detailed measures and practice experience of Hebei University of Science and Technology are given and have been applied. The practice results provide an overview of the bilingual teaching aspects on these professional courses. It is expected that this research can be helpful to the education study and reforms on the engineering curriculums of higher education level.
\end{abstract}

\section{Introduction}

With the process of china increasingly moving towards the world, accelerating towards internationalization and modernization, reforming the traditional teaching mode, exploring new educational methods which can high efficiently cultivate bilingual talents, that is an inevitable trend of adapting to the needs of social development, and also the inevitable result of the quality of education to further deepen [1,2]. Bilingual education practice of Canada and Western European countries, Hong Kong and Singapore have proved that the economic development of these countries and the implementation of bilingual education have a great relationship. "People-centered" is the most fundamental goal of bilingual education, is also the inevitable trend of education reform today $[3,4]$. When opening bilingual education, we must consider the characteristics of the course itself, so with carefully selection and preparation, professional of Automation of Hebei University of Science and Technology has opened the "Computer Network" bilingual teaching course in 2002 and the "Artificial Intelligence" bilingual teaching course in 2009.

\section{The Basic Model of Bilingual Education}

Three different modes of bilingual teaching are as follows:

Immersion Pro-gramme education: This mode requires teachers to use second language what students have learned / foreign language teaching, and mother language is not used in class and even in college, in order to allow students to immerse themselves in the disadvantaged language.

Transitional bilingual education: This mode requires that some subjects or all subjects use mother tongue when students come to the school. After a period of time, we should use the second language what they have learned / foreign language to teach.

Maintenance bilingual education: This mode requires that all subjects use mother tongue when students come to the school, and some subjects use second language what they have learned / foreign language after a period of time, but other subjects teaching is still the mother tongue[5].

At present, most domestic bilingual teaching adopt the third mode.

\section{The Bilingual Teaching Practice of Automation Major Course of Hebei University of Science and Technology}

\subsection{The Conditions of Achieving Bilingual Teaching in Major Course}

Depending on the actual situation of our school, we divide the process of the study into 3 stages: 
The stage of simple infiltration: During the classes, the teachers can represent important principles and keys in English so that the students have more opportunities to get in touch with English and the technical terms, so as to the students will gradually get used to the new teaching mode. The stage of integration: During the classes, the teachers can try to use English and Chinese alternately so that the students know how to describe the Chinese contents in English, and this will be a pretty good transition. The stage of bilingual thinking: The students try to think and answer questions in English in order to improving their abilities in using the second language comprehensively and skillfully.

Based on this, we prepared and searched carefully on the selection of professional courses, teaching staff, selection of teaching materials, students and so on.

\subsubsection{Setting Up Bilingual Teaching Courses Reasonably}

As we establish bilingual classes, we have to take into account of the feature of the course, such as the systematicness, continuity and the complexity of the course. It is not suitable to open a bilingual teaching course if the contents of the course are difficult, and the foreign original teaching materials and the teachers are lacked. Based on this, our major chose the "Computer Networks" and "Artificial Intelligence" as the bilingual teaching courses. For example, the "Computer Networks" has relatively strong international generality. There are abundant science and technology information, science and technology literature information, and international academic exchange information available for students to query. In addition, it can also play a role in popularizing the computer network knowledge.

\subsubsection{Optimizing Teaching Staff}

As the implementers of bilingual teaching, the teachers undoubtedly need solid professional foundation and relatively high English level. Except these, they have to build correct teaching concept. The point of the bilingual teaching is profession, and improving the students' ability in using English at the same time. At present, the teachers who teach bilingual course have the graduate student degree, master and doctor degree, and have taught "Subject English" and "Computer Network" for many years. They are familiar with the contents and the characteristics of the course, with more teaching experience, and more skillful in English and the basic of profession. What's more is that all of them had been studying in UK. So they have high ability of research and practice.

\subsubsection{Selection of the Classic Original Materials}

A good basis for successful bilingual teaching is to choose a suitable original material. Original materials of "Computer Network" are more, each has its own advantage. Due to the teaching purpose of automation course is to enable students to master the basic principles of computer networks, on this basis, making students to grasp the network application technology and understand network trends. Therefore, we selected classic "Computer Network" (Fourth Edition) of Andrew S.Tanenbaum, as well as its Chinese version "Computer Network" (Fourth Edition) as supporting material. Similar, the "Artificial Intelligence" also chooses the original foreign material elaborately based on the teaching program.

\subsubsection{The Case of the Students' own Foundation in English}

According to the professional training plan, "Computer Network" and "Artificial Intelligence" curriculums are put in junior and senior stages. Senior students have mastered basic English, have finished the professional learning of English as well as have the general understanding of cutting-edge computer networks and professional approach, so they have the ability of accepting and understanding the bilingual teaching content. 


\subsection{Implementation Measures in Bilingual Teaching of Specialized Course}

\subsubsection{Prepare Before Class, Adjust the Proportion of Using English Moderately}

In front of studying "Computer Network" course, for example, although there are quite a few students who often surf the Internet, but they know little about working principle and theory of knowledge about the network. Therefore, teachers hand out the professional vocabulary of the relevant sections in advance to students before class that can help students quickly become familiar with and master the relevant vocabulary, and improve speed of reading English textbooks. Although the claim of bilingual teaching is in English teaching, Chinese language is not rejected and we should allocate reasonable the proportion in using between them.

\subsubsection{Using a Variety of Teaching Methods, Enhancing Interactive Education}

Bilingual education programs have a large amount of information than the general curriculum, and the focus should be bilingual programs teaching in English and interaction with students, so on the basis of writing on the blackboard, using multimedia teaching can improve the efficiency in classroom teaching. Multimedia courseware can reduce the writing time on the blackboard, so that the whole teaching progress will be on plan. Meanwhile allowing teachers vividly demonstrate the implementation process of the algorithm, which is helpful for students to understand the algorithm. Students can download lesson plans at any time then student need not busy taking notes in class, and can have more time to listen to the teacher's explanation. In addition, teachers can introduce some related websites to let students download documents in order to open their field of vision, also can answer questions through the network after the lesson.

\subsubsection{Reforming the Inspection Way}

Usual homework and exams are effective methods of examining teaching effect. Assignments of the course are mainly taking the form of outside communication and English homework. Extracurricular exchange primarily is that teachers give students a course discussion topic, and students are required to access knowledge and discuss related projects. Some assignment in English are derived from the original teaching materials, and some exercises are translated from Chinese teaching materials. Students are required to use English to answer questions as much as possible, so they can improve English writing ability step by step.

The examination mainly takes the form of closed book exam (or open-book examination) all in English, and students are required to answer it in English. This part accounts for 70\%. Students' classroom speech, attendance, and homework are included in the total score as the usual score (accounts for 20\% 30\%).

\subsection{Teaching Effectiveness}

The teaching effectiveness of the above measures is of much significant after several sessions of students' teaching practice. Relevant statistical data is shown in Table 1.

Table1 Statistical data of bilingual education

\begin{tabular}{|c|c|c|c|c|}
\hline \multirow{2}{*}{ Project } & Content & Grade & Grade & Grade \\
& In English & 07 & 08 & 09 \\
\hline \multirow{3}{*}{ Homework } & $100 \%$ & $100 \%$ & $100 \%$ \\
\cline { 2 - 5 } & Self-expression and fluent language & $20 \%$ & $22 \%$ & $24 \%$ \\
\cline { 2 - 5 } & Reference books language & $34 \%$ & $35 \%$ & $38 \%$ \\
\cline { 2 - 5 } & Reference books and key words correctly & $26 \%$ & $25 \%$ & $24 \%$ \\
\hline \multirow{2}{*}{ Examination } & Answer in English & $84 \%$ & $88 \%$ & $90 \%$ \\
\cline { 2 - 5 } & Correct grammar and express clearly & $27 \%$ & $29 \%$ & $31 \%$ \\
\hline
\end{tabular}




\begin{tabular}{|c|c|c|c|c|}
\hline & $\begin{array}{c}\text { Expression is basically correct、having a } \\
\text { small amount of errors in grammar and } \\
\text { word }\end{array}$ & $31 \%$ & $34 \%$ & $35 \%$ \\
\cline { 2 - 5 } & $\begin{array}{c}\text { Key words are correct only and } \\
\text { expression is not clear enough }\end{array}$ & $22 \%$ & $20 \%$ & $19 \%$ \\
\hline Other & Hope to continue bilingual education & $70 \%$ & $71 \%$ & $73 \%$ \\
\hline
\end{tabular}

\section{Conclusion}

After a period of practice and exploration, we achieved some success, but there are also shortcomings to be improved. For example, continue to explore an appropriate proportion for bilingual education program among the total; create conditions to advocate and encourage teachers to further improve their English; writing bilingual materials themselves. In short, professional bilingual teaching mode is still in the exploratory stage. A bilingual teaching method suitable for course practice can be found only by trial and error, which can train the international talents to meet the needs of social development. This is the most fundamental purpose for Bilingual teaching.

\section{References}

[1] Zhang Fan, Wang Yili.: Explore of Bilingual Education of "Computer Network". Journal of Chongqing institute of technology, 21(3), (2007), p.159-161.

[2] Zha Bing, Sun Lixia.: Explore of Bilingual Education of "Principle and Application of Single-chip Microcomputer". China's adult education , Vol. 11 (2007), p.170-171.

[3] Ye Xuemei, Zhang Xiaoyun.: Research and Exploration of Bilingual Teaching in Computer Specialty. Higher Education of Engineering, (4), (2003), p.81-83.

[4] Hua Yu.: Practice and Discussion of Bilingual Teaching. Journal of Tangshan Normal University, 24(5), (2002), p.1-3.

[5] Zeng Yanbing, Li Hongqin.: Bilingual Teaching in Universities: Research of Definitions and Model. Nanchang Junior College, (1), (2005), p.69-71. 